\title{
Physics and the Public Mind
}

\section{By Prof. Herbert Dingle, Imperial College of Science, South Kensington}

$\mathrm{A}^{\mathrm{N}}$ epoch in science is invariably followed by a general change of attitude towards life as a whole, which is none the less profound because it lacks the dramatic suddenness of its precursor. Newtonian mechanics had no direct bearing on vulgar hopes and fears, yet the popular reaction to the appearance of a comet in the eighteenth century was not that of the sixteenth, even among those who knew nothing of gravitation. Organic evolution was not obviously concerned with sociology, yet to Spencer the word 'progress' meant something other than it meant to Rousseau. No scientific idea lives to itself or dies to itself.

The responsibility which this fact lays on the shoulders of the man of science weighs not on his researches but on his treatment of their results. By the very essence of his calling he is consecrated to truth, and he must know all her ways, whatever their effect on human institutions and beliefs. But, by the same token, he must see that his report on what he finds does not mislead; above all, that it does not contain a denial of the spirit of research itself.

For I say, this is death and the sole death, When a man's loss comes to him from his gain, Darkness from light, from knowledge ignorance.

Difficult as it must always be properly to estimate current events, it is clear beyond question that the post-War years have seen a development of fundamental physical ideas such as history has rarely recorded. Already the theoretical physicist of middle-age, if he has time to muse at all, contemplates the outlook of his youth with something of the feelings with which he regards medieval thought. It is only fitfully that he realises, with a mild shock of surprise, that this archaic attitude was once natural to himself and is still part of the mental equipment of most of "that section of his contemporaries which is called the public". On the world at large the impact of the new ideas must necessarily work more gently and slowly, but no less inevitably. Sooner or later, social institutions, literature, art, religion will reflect the change, and it is not too early to inquire how the public mind is reacting to the scientific revolution itself, for on that reaction will depend the more subtle developments in the various fields of practical human interest.

At first sight the omens are pleasing. Thanks largely to broadcasting and the great skill in exposition shown by certain of our physicists, popular attention is given to things scientific probably in greater measure than ever before. Not only so, but the recognition is general that science has something vital to contribute to the various departments of thought, feeling and action, and there is a genuine desire to know what that contribution might be. Superficially this is all very satisfactory.
When we look deeper into the phenomenon, however, grounds for misgiving appear. The remarkable fact that books of science have become best sellers admits of two possible explanations: either the most widespread desire of the public has changed, so that it is now for scientific thought instead of thoughtless diversion, or else books of science have changed so as to provide thoughtless diversion instead of scientific thought. Unfortunately the latter alternative appears to be nearer the truth.

There was a time when the writer of science for the public demanded considerable mental effort from his readers, as a tribute befitting the dignity of his subject. He showed them the steep and thorny way to heaven. Nevertheless he led them there if they were willing to follow him. To-day we are only too familiar with the primrose path to the everlasting bonfire. Writers such as Ball and Lockyer not only described the achieve. ments of science; they indicated also the steps towards those achievements, appealing to reason to approve the course as well as to admiration to applaud the goal. The modern successors of these men are too prone to present the achievements, made alluring by their plumage of paradox, and to prevent access to the steps by a mysterious guardian who, finger on lip, whispers in hushed tones the magic word, Mathematics. The consequence is inevitable. The reader not only enjoys the fun, but also feels at liberty to claim science in support of whatever philosophical or religious dogmas he may hold, paradox lending itself readily to favourable interpretation by contradictory creeds. Any scruples of conscience he may feel at taking this royal road to learning are allayed by the assurance that he need not think for himself since in any case the argument is beyond him. Small wonder that the age when science is most difficult is the age when it is most popular.

To make the point definite, let us concentrate attention on one of the most prominent elements of the new nescience-the doctrine of indeterminacy. It is widely preached that modern science is essentially indeterministic, and that therefore we may not only believe in human free will if we like-which, of course, we could always do-but also claim scientific support for it. This idea, emanating from men of science with the highest credentials, has spread, both directly and through various grades of intermediary expositors, to the pulpit, the newspaper and the market-place. Authority for the idea is everywhere; evidence for it, however, is far to seek. As an example we may cite an earnest little book recently written by a doctor of science with the object of showing the plain man the trend of modern science and philosophy. "The work of Dirac," he writes, "suggests a somewhat transcendental nature of matter, while that of Heisenberg is particularly 
significant because it has knocked the bottom out of the idea of predestination, put probability in its place, and shown that there is even a physical basis for the belief in free will as a factor of existence." When we seek for evidence for this remarkable statement, all we meet with is the following. "The mathematicians are among the most trustworthy of intellectual guides. Physics is essentially a mathematical subject, and over some of the ground we have to traverse the experimental physicist will still accompany us, but eventually we may have to trust the mathematician alone." When a doctor of science (who, it may be said, implies that he himself is unable to follow the mathematical arguments) can write in these terms, we may wonder whether the twentieth century differs intellectually from the sixteenth except in the substitution of the mathematician for the medieval philosopher.

The protest will at once be raised : 'What can one do? Theoretical physics is indisputably beyond expression in popular terms, and is one to keep some of the greatest intellectual adventures of history as a secret possession because they cannot be described in their fullness without mathematical language ?' The reply is that the evil does not lie in the incompleteness of the presentation-that must always exist-but in its character. Conclusions are presented as mathematically demonstrated which mathematics has not only not demonstrated but is also inherently incapable of demonstrating. Mathematics is thus portrayed as the magic wand of the few instead of the concentrated reason of all. Once the supreme expression and inspired Word of Reason, it has become an indulgence, granting absolution for the wildest excesses of irrationality. Instead of being a mental tonic, its very name has become a mental opiate, and elementary fallacies which a generation ago would have been detected by the most ordinary of thinkers, now deceive the acutest minds, which lie bemused under its spell.

To exemplify this it is not necessary to take the more outrageous application to human free will, which in actual fact has not yet been shown to bear any relation at all to physics. We can go deeper and look at the purely inorganic indeterminacy. The basic expression of this doctrine is to be found in Prof. Dirac's "Quantum Mechanics". "When an observation is made on any atomic system that has been prepared in a given way and is thus in a given state, the result will not in general be determinate, i.e., if the experiment is repeated several times under identical conditions several different results may be obtained." Let us see how this astonishing conclusion has been reached.

The whole of quantum mechanics, of which this is a part, has been built up as an attempt to explain the results of experiment. Now not only is it true that not one experiment has ever been repeated several times under identical conditions without the same result having been obtained (allowing, of course, as has always been done, for the small errors inevitable in human experiment), but the very statement which Dirac makes is based on this constancy. It will not do, for example, if he can say merely that a spectrum produced in Prof. Fowler's laboratory on such and such a date contained a line of which the wavelength on the following day appeared to Prof. Curtis to be so many units in terms of a scale which some years before had been found by an employee of Messrs. Hilger to bear a certain relation to a still earlier state of the standard metre. Unless he can say quite generally and definitely that the wave-length of $\mathrm{H} \alpha$ is that and nothing else, the whole system of quantum mechanics collapses for want of evidence. If, then, the conclusion quoted is true it automatically knocks away its own support and all reason for believing it vanishes.

This argument is very simple, and it is irrefutable. It makes no appeal to the algebra of matrices or group theory, but rests on the elementary logical principle that an argument whose conclusion violates its premises cannot be sound. Twenty years ago it would have occurred at once to any person of ordinary intelligence, but to-day what do we find? Half the world proclaim with joy that at last the most exact of sciences has established the freedom of the will, while the rest sit in bewildered silence, restraining the protest they long to make from fear that mathematics might have ways of disproving the obvious. The spectacle would be amusing if it were not so serious.

Let us understand the position clearly. It will not do to scoff at quantum mechanics and look upon the modern developments of physics as a malignant growth from which science may recover under the surgeon's knife ; they are, on the contrary, a mutation in the authentic line of development of thought. Dirac is not the fool he may superficially appear; he possesses one of the very greatest minds our age has produced. The fault is not that we are living in an age of darkness, but that the brilliance of the time is making us blind, that loss comes to us from our gain and ignorance from our knowledge. What is wanted is a reformulation of the philosophical foundations of science, so that sense shall not have to express itself in nonsensical terms. The philosopher may give it to us but there is more hope from the man of science, for in the present situation it is not so difficult for him to acquire sufficient philosophical knowledge and acumen as it is for the philosopher to familiarise himself with physics. But the manner of its coming is of minor import. ance : the great thing is to get it.

We are not unfamiliar with this demand or with attempts to satisfy it, but there is little sign that the real desideratum is properly understood. It is not sufficient to impeach Victorian assump. tions and declare how much wiser we are now. The new philosophy must not merely reveal the falsity of the old; it must embody all its truth. To resort once more to imagery, the relation of what we are offered to what we need is somewhat 
as follows. In surveying the physical landscape we have discovered certain facts which we cannot fit into the same plan as the more familiar ones: every attempt to co-ordinate them involves us in absurdity. There are two ways out of the difficulty. The first, which appears to be the only one attempted-or, at any rate, popularised-so far is to assume that the landscape is absurd, and that instead of marvelling that we cannot make a rational conception of it, we should rather pity our former inability to see that absurdity is the essence of Nature. The second way, which at least seems worth trying, is to change our point of view until the spectacle again becomes coherent. To do this is not easy : it is much pleasanter to lie in a bed of chaos and smile at our folly in thinking reason worth while. But the time may come when we shall regret such a choice.

It is a question for the specialist now, but in a few decades it will be a matter of universal importance; for the abstract thought of one generation, operating unperceived by the majority, directs the practical activities of the next. It is not merely scientifically indefensible, it is socially tragic when a tremendous forward leap in human thought, about which the public is curious to a degree never before witnessed, is represented as a negation, by an unintelligible formula, of all that has been proved trustworthy in the past; when a man like Sir Arthur Eddington, who is responsible for the most valiant attempt yet made to form a positive unity of the new ideas, can for public instruction give as a summary of the whole situation the vague and inaccurate phrase, "Something unknown is doing we don't know what"; when Sir James Jeans can so far forget his own admirable work as to write, "Heisenberg now makes it appear that Nature abhors accuracy and precision above all things"; and when the only means the truthseeker has of detecting the falsity of these statements-namely, the exercise of the reason with which he is naturally endowed-is made impotent by the suggestion that mathematics, which he has no time to learn, has discovered how to prove the illogical. There is here a situation far more serious in the long run than many of the problems which agitate public life to-day.

Freedom of thought may be attacked in two ways. Many recently have been moved to protest against the use of external force for this purpose. But, regrettable as such control is, it cannot by its very nature constitute a real limitation. Stone walls do not a prison make, and history has shown that the blood of the martyrs is the seed of the Church. Infinitely more dangerous is the menace to thought from thought itself. When, in the name of science, criticism is not chained but drugged, and unreason, in robes not its own, receives the homage meant for reason, thought is enslaved indeed. Those who are wise enough to see how the social life of a people is related to its mental state will scarcely contemplate the future with equanimity.

\section{Diet and Dental Disease in Man}

TT is now well established that there is an 1 intimate relationship between the structure of the teeth in animals and the composition of their food supply, as well as between the latter and certain forms of dental disease. The work of Mrs. Mellanby on these problems has already been referred to in these columns (NATURE, 125, 604 ; 1930. 127, 977 ; 1931). The results of these researches led naturally to an investigation of the problem of dental caries in human beings, along original lines, with the view of determining whether a similar relationship between diet and structure and disease held here also. An interim report of a clinical trial by the Committee upon Dental Disease was issued in 1931 (Nature, 129,83 ; 1932) and is now followed by the full account of Mrs. Mellanby's experiments upon the effect of diet on dental structure and disease in man*.

An account is given first of normal and abnormal development and structure of the teeth: by normal is meant the perfect structure which can be obtained in animals receiving vitamin $\mathrm{D}$ and a sufficiency of calcium and phosphorus. The normal tooth is creamy white, smooth and shiny in

\footnotetext{
* Medical Research Council. Special Report Series, No. 191 : Diet and the Teeth ; an Experimental Study. Part 3 : The Effect of Diet on Dental Structure and Disease in Man. By May Mellanby. Pp. 180. (London: H.M. Stationery Office, 1934.) 58. net.
}

appearance, the enamel is relatively thick and regular in outline, with a more or less regular, systematic arrangement of the prisms and comparatively little pigmentation. The dentine is relatively thick and shows no poorly calcified areas (or interglobular spaces). Such spaces are rare in animals living under natural conditions, but in civilised man, who lives under artificial conditions, their presence is the rule rather than the exception. Teeth can be graded according to the surface character of the enamel, even while still in the mouth: good correlation was found between surface texture and minute structure in the shed or extracted teeth submitted to microscopical examination, so that it is possible to infer the histological structure of teeth while still in the mouth.

In a collection of more than 2,000 shed and extracted teeth, it was found that, whether assessed by surface or histological examination, the majority of the deciduous teeth were defective (hypoplastic) in structure, the incisors being the best and the second molars the worst formed. Teeth collected from private sources were better calcified than those from public elementary school children. The majority of the permanent teeth were also hypoplastic. The teeth of two groups of children were also examined, the first in a hospital 